\title{
DESIGN E AS INTERFACES DE SERVIÇO
}

\author{
Fernando Secomandi \\ Universidade Federal de Juiz de Fora \\ fernando.secomandi@ufjf.edu.br
}

\begin{abstract}
Resumo: O design de serviço atualmente representa uma das principais ramificações do campo do design industrial. Este artigo traça um breve apanhado histórico dessa nascente disciplina e nota sua ainda tímida inserção no discurso acadêmico nacional. Como forma de contribuir para o fortalecimento da discussão sobre design de serviço no Brasil, são apresentadas diferentes perspectivas teóricas acerca do projeto de novos serviços. Em especial, discute-se abordagens voltadas para o projeto de interfaces materiais entre usuários e provedores. O artigo conclui com algumas considerações sobre implicações de projeto decorrentes de uma peculiaridade das relações de serviço: a presença de seres humanos na interface usuário-provedor.
\end{abstract}

Palavras-chave: design de serviço, design de interface, interface usuárioprovedor.

\section{INTRODUÇÃO}

É ainda incipiente, no Brasil, a discussão acadêmica sobre o design de serviço. Apesar da instalação nos últimos anos de alguns escritórios locais, como o live/work, da formação de grupos de pesquisa especializados, como o Desis (Coppe-UFRJ), e da organização do primeiro - e único - Simpósio Brasileiro de Ciência de Serviços, a produção acadêmica nacional permanece aquém da crescente atenção dada ao tema "serviços" no âmbito internacional da pesquisa e prática do design. Tal descompasso se revela problemático diante da constatação que o impacto econômico do setor de serviços, assim como nas economias ditas mais avançadas, revela-se imenso também em diversos vários emergentes, incluindo o Brasil.

Talvez fosse possível explicar o atraso brasileiro como fruto da demora generalizada, também observada em outros países, entre a simples percepção da importância econômica das atividades de serviço e o real entendimento dos mecanismos de inovação inerentes a elas. Embora o debate econômico sobre serviços 
já perdure por mais de trezentos anos (DELAUNAY; GADREY, 1992), foi só por volta dos anos 1980, aproximadamente, que pesquisadores no campo da administração passaram a se debruçar sobre processos de gestão e desenvolvimento de novos serviços, dos quais o design é peça fundamental (PAPASTATHOPOULOU; HULTINK, 2012).

No marketing, especificamente, o design de serviço tornou-se tema de interesse acadêmico através das contribuições pioneiras de Shostack (1984), entre outros especialistas. Livros introdutórios sobre marketing de serviço há muito já dispunham de pelo menos um capítulo a tratar de questões relativas ao projeto de novos serviços. Ainda assim, a necessidade de maiores aportes teóricos e metodológicos sobre o assunto foi lembrada com certa preocupação em diversas ocasiões. Gummesson (1994, p. 85), de forma bastante evocadora, notou essa carência ao proferir: "não há nenhuma metodologia genérica para o design de serviços; não há uma profissão chamada designer de serviço".

Passadas duas décadas, a situação identificada por Gummesson já não se encontra igual. A partir da década de 1990 e, mais decididamente, depois dos anos 2000, designers passaram a se interessar pelos serviços. Em uma das poucas publicações disponíveis em língua portuguesa, Freire e Damazio (2010) elencam alguns dos movimentos embrionários da disciplina do design de serviço, entre eles, o livro precoce, para o ano em que foi escrito - de Hollins e Hollins (1991), o doutorado de Pacenti no Politécnico de Milão (Itália), a nomeação de Birgit Mager para a cátedra de design de serviço na Universidade de Ciências Aplicadas de Colônia (Alemanha) e a formação do Service Design Network, que, subsequentemente lançou o primeiro periódico especializado, chamado Touchpoint.

A esses movimentos, pode-se acrescentar, ainda, o surgimento de consultorias especializadas em design de serviço (live/work e Engine, na Grã-Bretanha), a organização das primeiras conferências internacionais (Emergence 2007, Estados Unidos; International Service Innovation Design Conference 2008, Coreia do Sul; Service Design Network Conference 2008, Holanda; ServDes 2009, Noruega), a publicação de artigos em periódicos de reconhecida importância no campo do design (p. ex. (MORELLI, 2002, 2003), bem como uma ampla mobilização por meios de comunicação eletrônicos (p. ex. o blog de Jeff Howard "Design for Service", [s.d.]).

Adentrando-se o segundo decênio dos anos 2000, torna-se impossível detalhar a evolução dos estudos sobre design de serviço sem recorrer à redação de um novo artigo. Portanto, para fechar este breve apanhado histórico, basta observar que alunos fluentes no idioma inglês atualmente contam com diversos livros introdutórios sobre a teoria e prática do design de serviço (p. ex. MERONI; SANGIORGI, 2011; STICKDORN; SCHNEIDER, 2011), bem como cursos de especialização ou mestrado oferecidos por universidades de renome, incluindo Royal College of Arts (Inglaterra) e Politécnico de Milão (Itália).

O presente trabalho tem como objetivo contribuir para o fortalecimento da discussão acadêmica sobre design de serviço no Brasil. Para tanto, aborda uma questão de fundamental relevância: como descrever os serviços sob a ótica da prática projetual? Em outras palavras, o que os designers projetam nos serviços? A resposta que se propõe a seguir é que o design, em última instância, ocupa-se do projeto das interfaces de serviço, as quais também são conhecidas como os 'pontos-de-contato' (touchpoints) entre usuários e provedores de um determinado serviço. Por exemplo, o transporte público metroviário normalmente compreende diversas interfaces usuário-provedor, 
incluindo a arquitetura e ambientação das estações, os sistemas de sinalização, os pontos de venda informatizados e/ou operados por humanos, os trens etc.

Que a produção de qualquer serviço se dá por meio da interação entre usuários e provedores, isso não é nenhuma descoberta original dos designers. Segundo Gallouj e Weinstein (1997, p. 541), pesquisadores de diversas matizes disciplinares fizeram uso do conceito de interface ou de noções similares ao tentar descrever as relações de serviço. Porém, na projeto de design, a interface assume ponto nevrálgico. A seguir, serão discutidos três marcos teóricos sobre o projeto das interfaces de serviço. 0 primeiro representa as contribuições de Shostack (1977, 1982, 1984, 1987) na área do marketing de serviço. Shostack talvez tenha sido a primeira a considerar a interface usuário-provedor uma parte integrante do projeto sistemático de novos serviços. A segunda contribuição é de Pacenti (2004), que se inspira em conceitos advindos do design de interação e propõe que o design de serviço configura-se, primordialmente, como o projeto das interfaces usuário-provedor. Por fim, Secomandi (2012; 2013) incorpora avanços no campo da filosofia da tecnologia e elabora uma fenomenologia da experiência humana das interfaces de serviço. A conclusão deste artigo inclui uma discussão sobre uma característica bastante peculiar dos serviços: a presença de humanos na interface.

\section{SHOSTACK: A INTERFACE TANGÍVEL}

Em 1977, Shostack publicou Breaking Free from Product Marketing, artigo que contribuiu enormemente para a consolidação da disciplina do marketing de serviço. A tese defendida por Shostack era que o marketing não dispunha de subsídios conceituais para lidar adequadamente com a natureza intangível dos serviços. Diferentemente dos produtos, de acordo com Shostack (1977, p. 75-76) serviços "não podem ser tocados, experimentados em termos de tamanho, ou dispostos numa prateleira". Isso não significa que produtos, por outro lado, sejam completamente tangíveis. Um carro, por exemplo, é um produto, pois baseia-se essencialmente em elementos tangíveis, como motor, volante, bancos etc. Embora carros também possam incluir elementos intangíveis, como transporte, para Shostack os serviços são primordialmente formados por tais elementos. Por serem intangíveis por natureza, serviços só podem ser vivenciados por consumidores por meio da "evidência tangível" (tangible evidence), isto é, "as coisas que o consumidor pode compreender com seus cinco sentidos" (SHOSTACK, 1977, p. 77). Num serviço de aviação, por exemplo, a evidência tangível tipicamente inclui aviões, uniformes, lanches, entre outros elementos.

Além de sua contribuição teórica, Shostack (1982) foi responsável pela criação de um dos primeiros métodos para o projeto sistemático de novos serviços: o service blueprinting. No blueprint (ou esquema, mapa, plano) de um serviço, a evidência tangível serve como ponto de referência para o mapeamento dos processos de prestação de serviço que são internos à empresa provedora. Por exemplo, ao abrir uma conta bancária, clientes normalmente entram em contato com o serviço do banco através da evidência tangível formada pelo consultor financeiro, o formulário de inscrição e a agência onde a consulta ocorre. Eventualmente, esse mesmo cliente perceberá o término da relação de serviço após o recebimento de uma carta quando do encerramento do contrato, ou seja, através de uma outra forma de evidência tangível. Partindo-se desses dois momentos, pode-se então identificar e descrever uma série de processos organizacionais sob responsabilidade do banco, imprescindíveis à prestação 
do serviço, como consultas a bases de dados, cálculo de rendimento e um tanto mais, porém, que não podem ser observados pelo cliente. Segundo Shostack, esses processos encontram-se além da "linha de visibilidade" e são julgados pelo cliente, não diretamente, mas pela forma como se manifestam através da evidência tangível do serviço.

Na medida em que seu trabalho sobre o design de serviço avançou, Shostack (1987) tornou-se convencida de que serviços são, em essência, processos imateriais. Segundo Shostack, a ferramenta blueprint serve para promover uma espécie de "re-engenharia" desses processos, os quais, em analogia aos produtos, representam a "matéria-prima" dos serviços (SHOSTACK, 1987, p. 34). Dessa forma, ainda que Shostack afirme que a evidência tangível dos serviços representa a "realidade" dos serviços do ponto de vista do consumidor, e que o design de serviço deve compreender a "orquestração" dessa evidência, em última análise a abordagem de design preconizada por Shostack privilegia o projeto dos processos imateriais de prestação de serviços vis-à-vis o projeto das interfaces materiais entre usuários e provedores.

\section{PACENTI: A INTERFACE POTENCIAL}

Se Shostack abordou a interface usuário-provedor como elemento periférico no projeto de novos serviços, Pacenti (2004), por sua vez, tornou-a objeto central da atividade de design. Sua proposta funda-se na integração de estudos nas áreas da economia e da administração dos serviços com avanços no então recente campo do design de interação. Pacenti observa que a crescente digitalização e computerização dos processos de produção de serviços reestruturava de forma significativa a interação entre usuários e provedores. Como forma de compreender melhor esta transformação proporcionada pela tecnologia, Pacenti estabelece uma analogia entre o conceito de evidência tangível dos serviços e o de interface do usuário (user interface). Tal qual Shostack, do ponto de vista do usuário, o serviço se resumiria a experiência da interface:

"O serviço pode ser observado como um sistema organizacional complexo, ou apenas a partir de sua interface. Do ponto de vista do usuário, a imagem e identidade do serviço (o que oferece e como funciona) se concretiza na sua interface, naquilo que ele experimenta, vê e sente, e pouca importância tem, a fins da interação, a estrutura organizacional que está por trás." (PACENTI, 2004, p. 158)

Diferentemente de Shostack, e valendo-se de conhecimentos do design de interação, Pacenti conclui disso que a interface constitui o principal foco da atividade de projeto:

“A apropriação de ferramentas conceituais do design de interfaces permite que se aproxime de uma abordagem em que a estrutura organizacional do serviço passa em segundo plano, como a engenharia de um objeto técnico, para dar lugar a questões de projeto da sua qualidade não só técnica, mas também cultural." (PACENTI, 2004, p. 159)

Segundo Pacenti, em analogia às tecnologias interativas, a experiência da interface de serviço pode ser qualificada de duas formas. Em primeiro lugar, Pacenti 
ressalta a dimensão temporal da interface. A interface não é algo inerte, um simples agrupamento de objetos materiais. Ela manifesta-se no tempo e interage com as ações e os comportamentos dos usuários. Em segundo lugar, Pacenti define a interface de serviço como um evento em potencial, ou seja, que só se atualiza quando da interação com o usuário.

Com base nessas observações, Pacenti (2004, p. 159-161) conclui que o projeto das interfaces de serviço se assemelha à uma "encenação" ou "coreografia", pois designers não devem especificar completamente a interface em sua dimensão puramente material, mas sim criar interfaces que possibilitassem uma ampla gama de "performances" em interação com usuários.

\section{SECOMANDI: A INTERFACE MEDIADORA}

Partindo dos pressupostos estabelecidos por Shostack e Pacenti - que serviços compreendem uma interface usuário-provedor e que esta configura-se como objeto de projeto para designers - Secomandi (2012) busca na filosofia da tecnologia, mais precisamente em estudos de linha pós-fenomenológica, recursos para melhor entender a experiência humana dos serviços. Segundo sua abordagem, interfaces de serviço mediam relações entre usuários (ou provedores) e o serviço em questão. Porém, diferentemente de Shostack e Pacenti, para Secomandi as interfaces de serviço não são simplesmente objetos pré-definidos, que se posicionam "entre" pessoas e um determinado serviço; as interfaces em parte constituem usuários e serviço como tais.

Como forma de ilustrar o processo de constituição recíproca entre usuários e interfaces de serviço, Secomandi (2013) realiza um estudo empírico sobre um serviço de base tecnológica recentemente comercializado por uma empresa global de eletrônicos. Esse serviço tem como propósito ajudar pessoas a se tornarem mais ativas fisicamente e, consequentemente, mais saudáveis. Secomandi demonstra como suas diferentes interfaces influenciam a experiência que usuários têm de suas próprias atividades corporais, condicionamento físico e identidades sociais. Portanto, mais do que meramente projetadas para proporcionar a usuários "acesso" aos recursos controlados por um provedor de serviço, interfaces materiais podem também transformar a experiência e o conhecimento que uma pessoa tem de si própria.

"É através da materialidade da interface que designers podem influenciar como pessoas são constituídas como clientes, em primeiro lugar, e continuamente transfiguradas nas suas relações com o provedor do serviço....Porque nenhum serviço pode existir a não ser através de uma interface material, aí está o verdadeiro desafio para designers de serviço ajudarem a catalisar transformações sociais." (SECOMANDI, 2013)

Em outro artigo, a aplicação do referencial pós-fenomenológico às interfaces de serviço resulta na identificação de quatro tipos de interação usuário-interface (SECOMANDI; SNELDERS, 2012). Primeiramente, na relação de "incorporação" (embodiment) a interface de serviço torna-se uma extensão parcial do aparelho sensório-perceptivo do usuário. Na relação "hermenêutica" (hermeneutic), o usuário interpreta o mundo ao redor a partir do que é visualizado através da interface de serviço. Na relação de "alteridade" (alterity), o usuário interage diretamente com a interface de serviço, enquanto aspectos do mundo ao redor são postos no segundo plano da 
experiência. Por fim, na relação de "pano de fundo" (background) o usuário "relega" a interface de serviço a um plano contextual de sua interação imediata com aspectos do mundo. Ao descrever esses modos de interação, Secomandi e Snelders almejam oferecer uma ampla gama de objetivos a serem buscados por designers durante 0 projeto de novos serviços com foco nos usuários.

\section{DISCUSSÃO}

A apresentação de forma encadeada das propostas de Shostack, Pacenti e Secomandi, acima, sugere uma certa trajetória evolutiva no pensamento sobre interfaces de serviço. Embora o objetivo da exposição tenha sido ressaltarcada proposta no que ela contém de original, isso não significa que conceituações mais recentes superem ou automaticamente tornem obsoletas outras precedentes. Por exemplo, muitos designers de serviço continuam a ecoar as ideias de Shostack ao vincularem o projeto de interface à necessidade de "tangibilização" dos serviços que, em essência, seriam imateriais.

Mesmo que o atual discurso acadêmico comporte uma diversidade de opiniões, a realização comum que o projeto de interfaces materiais é uma atividade essencial do design de serviço abre espaço para comparações interessantes entre a natureza desta nascente disciplina e design industrial amplamente considerado. Uma das considerações que podem ser traçadas remete à definição de design formulada décadas atrás por Maldonado (1991) e, ao que parece, relevante ainda hoje. Maldonado buscava a legitimação acadêmica do design frente a práticas projetuais correlatas, como a engenharia, o artesanato e a arte aplicada, todas significativamente impactadas pela industrialização dos processos produtivos. Para Maldonado (1991, p. 16-17) o design tem como tarefa "mediar dialecticamente entre necessidades e objetos, entre produção e consumo"; e, mais concretamente, "coordenar, integrar e articular todos aqueles fatores que, de uma maneira ou de outra, participam no processo cons titutivo da forma de um produto" (MALDONADO, 1991, p. 14).

$\mathrm{O}$ advento de sociedades pós-industriais, em parte movido pela arrebatadora expansão do setor de serviços, oferece uma nova oportunidade de reflexão sobre o papel do design. À luz da explanação oferecida neste texto, pode-se relacionar o conceito da interface usuário-provedor ao que Maldonado se referia como "forma do produto". No contexto de sociedades industriais, a interface tomaria a forma de um objeto material altamente padronizado, resultado de processos mecânicos de manufatura em série. Em contextos pós-industriais, que forma teria a interface dos serviços?

Ainda que seja impossível, no âmbito deste artigo, detalhar todos os fatores constitutivos da forma aludidos pela definição de Maldonado, vale ressaltar um que é bastante peculiar às relações de serviço: o contato interpessoal entre seres humanos. Diferentemente do que ocorre na produção de bens industriais, serviços tipicamente não dependem da transmissão de posse sobre um objeto físico entre produtores e consumidores. Numa consulta médica, por exemplo, a relação interpessoal que se estabelece entre médico e paciente é o aspecto preponderante da interface de serviço. Essa interação é um tanto diferente da experiência de bens industriais, onde um produtor humano é intuído indiretamente por usuários, isto é, através do resultado material do seu trabalho. 
Retornando às contribuições de Shostack, Pacenti e Secomandi, cada um desses autores oferece uma visão, porém não bastante elaborada, sobre o projeto da faceta humana das relações de serviço. Shostack $(1977$, p. 79) observa que há casos em que "a pessoa [humana] é percebida como sendo o serviço". Segundo ela, por terem "um impacto material na percepção do consumidor", pessoas integram a evidência dos serviços, tal qual outros elementos tangíveis (SHOSTACK, 1982, p. 53). Shostack (1977, p. 79) chega ao ponto de defender que o design da evidência contemplaria, por exemplo, a "embalagem" de um candidato político por parte de um comitê que lhe determinasse quais palavras usar ou que corte de cabelo adotar.

Pacenti, por outro lado, é mais criteriosa a respeito da presença do elemento humano nas interfaces de serviço. Ela observa que provedores humanos aumentam o grau de variação na realização da performance potencial dos serviços. Do ponto de vista do projeto de design, o comportamento desses provedores não poderia ser especificado tão diretamente como outros componentes materiais da interface o são. Designers se limitariam a influenciar os prestadores humanos de serviço através do projeto do ambiente físico, por exemplo. No máximo, no caso de interações intermedia das por um artefato tecnológico (p. ex. uma ligação telefônica), o projeto da interface poderia contemplar aspectos periféricos da prestação do serviço, "no tom pessoal ou 'friendly' do operador, na qualidade (seja automatizada ou ao vivo) da som e do som, em pequenos rituais de cortesia" (PACENTI, 2004, p. 162).

Secomandi (2012, p. 119-154), por fim, enfrenta algumas dificuldades decorrentes de sua abordagem pós-fenomenológia, inicialmente pensada para a interação humano-tecnologia. Após uma cuidadosa reformulação de alguns pressupostos dessa abordagem, Secomandi defende que partes do corpo humano, ou aspectos intimamente associados a ele, podem ser abordados sob a ótica projetual como interfaces de serviço. Isso não significaria que humanos devam ser "projetados" de forma semelhante a outros aspectos da interface material dos serviços. Tampouco que se deva, por outro lado, excluir a interação humano-humano do foco da atividade de projeto. Para Secomandi, as interfaces humanas possuem características próprias que confrontam designers com novos desafios e oportunidades para a reformulação de suas especialidades profissionais. Secomandi chega a sugerir, provocadoramente, que designers têm muito o que aprender sobre o projeto de novos serviços com profissionais como cabeleireiros, assimcomo foram capazes, no passado, de assimilar conhecimentos de outros profissionais dedicados ao projeto de produtos industriais, como os engenheiros.

\section{REFERÊNCIAS}

DELAUNAY, J.-C.; GADREY, J. Services in Economic Thought: Three Centuries of

Debate. Springer, 1992.

Design for Service. Disponível em: <http://designforservice.wordpress.com/>. Acesso em: 13 mai. 2014.

FREIRE, K. DE M.; DAMAZIO, V. Design de serviços: conceitos e reflexões sobre o futuro da disciplina. $9^{\circ}$ Congresso Brasileiro de Pesquisa e Desenvolvimento em Design. Anais... São Paulo: Blücher e Universidade Anhembi Morumbi, 2010 
GALLOUJ, F.; WEINSTEIN, O. Innovation in Services. Research Policy, v. 26, p. 537-556, 1997.

GUMMESSON, E. Service Management: An Evaluation and the Future. International Journal of Service Industry Management, v. 5, n. 1, p. 77-96, 1994.

HOLLINS, G.; HOLLINS, B. Total Design: Managing the Design Process in the Service Sector. London: Pitman, 1991.

MALDONADO, T. Design industrial. Edições 70, 1991.

MERONI, A.; SANGIORGI, D. Design for Services. Aldershot: Gower, 2011.

MORELLI, N. Designing Product/Service Systems: A Methodological Exploration. Design Issues, v. 18, n. 3, p. 3-17, 2002.

MORELLI, N. Product-Service Systems, a Perspective Shift for Designers: A Case Study: The Design of a Telecentre. Design Studies, v. 24, n. 1, p. 73-99, 2003.

PACENTI, E. Design dei servizi. In: BERTOLA, P.; MANZINI, E. (Eds.). Design multiverso: Appunti di fenomenologia del design. Milano: Edizioni POLI.design, 2004. p. 151-164.

PAPASTATHOPOULOU, P.; HULTINK, E. J. New Service Development: An Analysis of 27 Years of Research. Journal of Product Innovation Management, v. 29, n. 5, p. 705714, 2012.

SECOMANDI, F. Interface Matters: Postphenomenological Perspectives on Service Design. Tese (doutorado)-Delft: Delft University of Technology, 2012.

SECOMANDI, F. Thinking through the Service Interface: A Study of Philips DirectLife. Design Philosophy Papers, n. \#1 / 2013, 2013.

SECOMANDI, F.; SNELDERS, D. Interface Design in Services: A Postphenomenological Approach. Design Issues, v. 29, n. 1, p. 3-13, 12 dez. 2012.

SHOSTACK, G. L. Breaking Free from Product Marketing. Journal of Marketing, v. 41, n. 2, p. 73-80, 1977.

SHOSTACK, G. L. How to Design a Service. European Journal of Marketing, v. 16, n. 1, p. 49-63, 1982.

SHOSTACK, G. L. Designing Services that Deliver. Harvard Business Review, v. 62, n. 1, p. 133-139, 1984.

SHOSTACK, G. L. Service Positioning through Structural Change. Journal of Marketing, v. 51, n. 1, p. 34-43, 1987.

STICKDORN, M.; SCHNEIDER, J. (EDS.). This Is Service Design Thinking: Basics-ToolsCases. Amsterdam: BIS Publishers, 2011. 
